\title{
Changes in REVEAL risk score in patients with pulmonary arterial hypertension treated with macitentan in clinical practice: results from the PRACMA study
}

Pilar Escribano-Subias ${ }^{1,2^{*}}$, Raquel López ${ }^{3}$, Luis Almenar ${ }^{3}$, María Lázaro ${ }^{4}$, lan Forn ${ }^{5}$, Anna Torrent ${ }^{5}$, Isabel Blanco ${ }^{6}$, Joan Albert Barberà ${ }^{6}$ and on behalf of the PRACMA investigators

\begin{abstract}
Background: Macitentan is a dual endothelin receptor antagonist indicated for the long-term treatment of pulmonary arterial hypertension (PAH). We evaluated the change over time in REVEAL risk score in incident and prevalent patients receiving macitentan for the first time.

Methods: Retrospective, observational study including adult patients with idiopathic/heritable PAH or PAH associated with connective tissue disorders or congenital heart disease treated with macitentan for $\geq 6$-month follow-up in Spain. The REVEAL risk score and risk strata were computed at the start of macitentan and after $\geq 6$ month in patients with $\geq 7$ out of 12 valid REVEAL components.

Results: Overall, 81 patients (57 for the REVEAL score) were analysed, $77.8 \%$ women. The mean age was 57.2 years and $50.6 \%$ of patients had idiopathic/heritable PAH. Prevalent patients were 59.3 and $40.7 \%$ were incident. Main therapies for PAH included macitentan monotherapy (42.0\%) and macitentan in combination with phosphodiesterase type 5 inhibitor (44.4\%). With a median time of macitentan treatment of 10.5 months, the mean REVEAL score was 8.7 points at baseline and was 7.2 points after $\geq 6$-month follow-up. The mean change (95\% Cl) in REVEAL risk score was $-1.4(-2.0,-0.9)$ points $(p<0.0001)$, being $-1.8(-3.0,-0.7)$ points $(p=0.0040)$ and -1.2 $(-1.8,-0.5)$ points $(p=0.0010)$, in incident and prevalent patients, respectively. The reduction was also significant by risk stratum (36.8\% of patients in the high-very high risk strata at baseline versus $14.0 \%$ after $\geq 6$-month, $p<0.05$ ) and therapy group. The REVEAL components that significantly improved were WHO functional class (FC) (63.9\% FC III at macitentan initiation and 23.6\% after $\geq 6$-month, $p<0.0001$ ), 6 -min walk test (mean change: $41.8 \mathrm{~m}, p<0.01$ ), brain natriuretic peptide (BNP) or N-terminal proBNP (NT-proBNP) (mean change of $-157.6 \mathrm{pg} / \mathrm{mL}$ and $-530.0 \mathrm{pg}$ / $\mathrm{mL}$, respectively, $\mathrm{P}<0.05$ both), and pulmonary vascular resistance (PVR) (mean change: $-3.4 \mathrm{WU}, \mathrm{p}<0.01$ ).

(Continued on next page)
\end{abstract}

\footnotetext{
* Correspondence: pilar.escribano.subias@gmail.com

'Pulmonary Hypertension Unit, Cardiology Department, Hospital Universitario

12 de Octubre, Av. Córdoba, s/n, 28041 Madrid, Spain

${ }^{2}$ CIBER de Enfermedades Cardiovasculares (CIBERCV), Instituto de

Investigación Sanitaria Hospital 12 de Octubre (imas12), Av. Córdoba, s/n,

28041 Madrid, Spain

Full list of author information is available at the end of the article
}

C C The Author(s). 2020 Open Access This article is licensed under a Creative Commons Attribution 4.0 International License, which permits use, sharing, adaptation, distribution and reproduction in any medium or format, as long as you give appropriate credit to the original author(s) and the source, provide a link to the Creative Commons licence, and indicate if changes were made. The images or other third party material in this article are included in the article's Creative Commons licence, unless indicated otherwise in a credit line to the material. If material is not included in the article's Creative Commons licence and your intended use is not permitted by statutory regulation or exceeds the permitted use, you will need to obtain permission directly from the copyright holder. To view a copy of this licence, visit http://creativecommons.org/licenses/by/4.0/ The Creative Commons Public Domain Dedication waiver (http://creativecommons.org/publicdomain/zero/1.0/) applies to the data made available in this article, unless otherwise stated in a credit line to the data. 
(Continued from previous page)

Conclusions: In this study, treatment with macitentan improved the REVEAL risk strata and score in both incident and prevalent PAH patients, and in all patients regardless of the therapy strategy. Macitentan significantly improved some of REVEAL components including WHO FC, BNP/NT-proBNP, PVR, and 6-min walk test after at least 6-month follow-up.

Keywords: Macitentan, Observational study, Pulmonary arterial hypertension, Risk assessment

\section{Background}

Pulmonary arterial hypertension (PAH) is a progressive disease characterised by an increased mean pulmonary arterial pressure of at least $25 \mathrm{mmHg}$ at rest and a pulmonary vascular resistance (PVR) greater than $3 \mathrm{Wood}$ units (WU) [1,2] with low incidence and prevalence in the general population $[3,4]$, and a poor prognosis without therapy in terms of mortality [2]. In Spain, the estimated incidence of PAH ranges from 2.4 to 7.6 cases/ million/year [5]. The 1-year survival rate of newly diagnosed PAH patients may be predicted using a risk score calculator derived from the Registry to Evaluate Early and Long-term PAH Disease Management (REVEAL) [6, 7]. Data from this registry reported that PAH patients had 1-year survival rate of $85 \%$ and 5-year survival rate of $57 \%$ from the time of diagnosis [8].

Endothelin receptor antagonists emerged as an important therapeutic option for PAH in the late 1990s [9]. Among these agents, macitentan is an oral agent with dual endothelin receptor antagonist function, which is indicated as monotherapy or in combination for the long-term treatment of $\mathrm{PAH}$ in adult patients of World Health Organization (WHO) functional class (FC) II to III. Efficacy has been shown in a PAH population including idiopathic and heritable $\mathrm{PAH}, \mathrm{PAH}$ associated with connective tissue diseases, and $\mathrm{PAH}$ associated with repaired congenital heart disease [10].

As REVEAL risk score changes over time in most PAH patients, ongoing risk score assessments can identify changes in disease course and thus, help optimizing therapeutic strategies in PAH [11]. The primary objective of this observational study was to assess the change over a minimum period of six months in REVEAL risk score and risk strata in PAH patients receiving maciten$\tan$ for the first time in Spain. The secondary objectives were to describe patients' characteristics and treatment patterns, and assess the changes in individual parameters of the REVEAL score components in PAH patients.

\section{Methods}

The PRACMA was a retrospective observational study with at least 6-month follow-up. The inclusion criteria were adult patients with idiopathic or heritable PAH, $\mathrm{PAH}$ associated with connective tissue disorders or PAH associated with corrected simple congenital heart disease of WHO FC II to III, and treated for the first time with macitentan $10 \mathrm{mg}$ once daily, either in monotherapy or in combination, for at least six months. The protocol was approved by the independent ethics committee at each study site.

The study was conducted in 28 centres from Spain between September 2016 and September 2017. Study data was collected from medical records, with data collected at baseline (within a maximum of 4-month prior to the start of macitentan) and at least 6-month (175 days) after treatment initiation. Demographics (gender, age), WHO group I subgroup (idiopathic or heritable $\mathrm{PAH}, \mathrm{PAH}$ associated with connective tissue disorders, or PAH associated with corrected simple congenital heart disease), $\mathrm{PAH}$ diagnosis date, onset date for macitentan as well as other therapy for PAH were collected at baseline. The following variables were collected at both baseline and $\geq$ 6-month time points: presence of renal insufficiency, WHO FC (I to IV), vital signs (systolic blood pressure [SBP] and heart rate), 6-min walk test, laboratory data (brain natriuretic peptide [BNP] or N-terminal proBNP [NT-proBNP]), echocardiogram (pericardial effusion), pulmonary function test data (diffusing capacity of the lungs for carbon monoxide [DLCO]), and hemodynamic parameters related to right-heart catheterization (mean right atrial pressure [mRAP] and PVR).

\section{Statistical analysis}

The evaluable population comprised those patients with at least 175 days of treatment with macitentan and at least one valid value for any of the components of the REVEAL score (WHO FC, vital signs, 6-min walk test, laboratory data, echocardiogram, pulmonary function test, or hemodynamic parameters) either at baseline or at $\geq 6$-month time points.

Due to the inclusion of similar ratio of incident and prevalent patients, it was decided to analyse them separately. Incident patients were defined as patients diagnosed less than six months prior to the start date of macitentan. Patients were defined as prevalent if the $\mathrm{PAH}$ diagnosis date was equal or greater than six months prior to the start date of macitentan.

Descriptive analyses were provided for all variables. The presence of renal insufficiency was based on the comorbidity being recorded in the patient's medical record. 
The REVEAL risk score was computed at baseline and at $\geq 6$-month time points according to the REVEAL risk score calculator and selecting patients with at least 7 out of 12 valid REVEAL components [6] at both time points (REVEAL population). All men who turned $>60$ years old during the course of the $\geq 6$-month period were counted in the "Men aged $>60$ years" category. No missing imputation was performed. Risk scores ranged from 0 (lowest risk) to 22 (highest risk). Risk categories by risk score were 1-7 low risk, 8 average risk, 9 moderate high risk, 10 or 11 high risk, and $\geq 12$ very high risk.

For analysis of risk categories, the average and moderate high categories were grouped $[8,9]$ as well as the high and very high categories $(\geq 10)$ due to the low frequencies in these categories. REVEAL score was analysed computing the mean change between $\geq 6$-month and baseline REVEAL score and corresponding 95\% confidence interval. For continuous components the change between visits has been addressed computing a point estimate of mean and median difference between baseline and $\geq 6$-month as well as their confidence interval. For categorical components we have computed the proportion of events at both baseline and $\geq 6$-month visits and corresponding 95\% confidence interval for the difference. Wilcoxon matched pairs signed rank test and t-paired test were applied and a sensitivity analysis excluding three outliers for change was performed.

For the comparisons between incident and prevalent patients, Mann-Whitney $U$ test and chi-square test were used for continuous and categorical variables, respectively. For continuous individual REVEAL components, changes over time were compared with the Wilcoxon matchedpairs signed-rank test. For categorical REVEAL components, changes over time were compared with the $\mathrm{McNe}$ mar test. A $p$-value of $<0.05$ was considered significant.

Statistical analyses were performed with the Stata Statistical Software version 15 (College Station, TX: StataCorp LLC).

\section{Results \\ Baseline characteristics}

A total of 88 patients were enrolled and 81 were included in the analysis (mean of 2.9 patients per site), of whom 57 (70.4\% of evaluable population) were valid to compute the REVEAL risk score (Fig. 1).

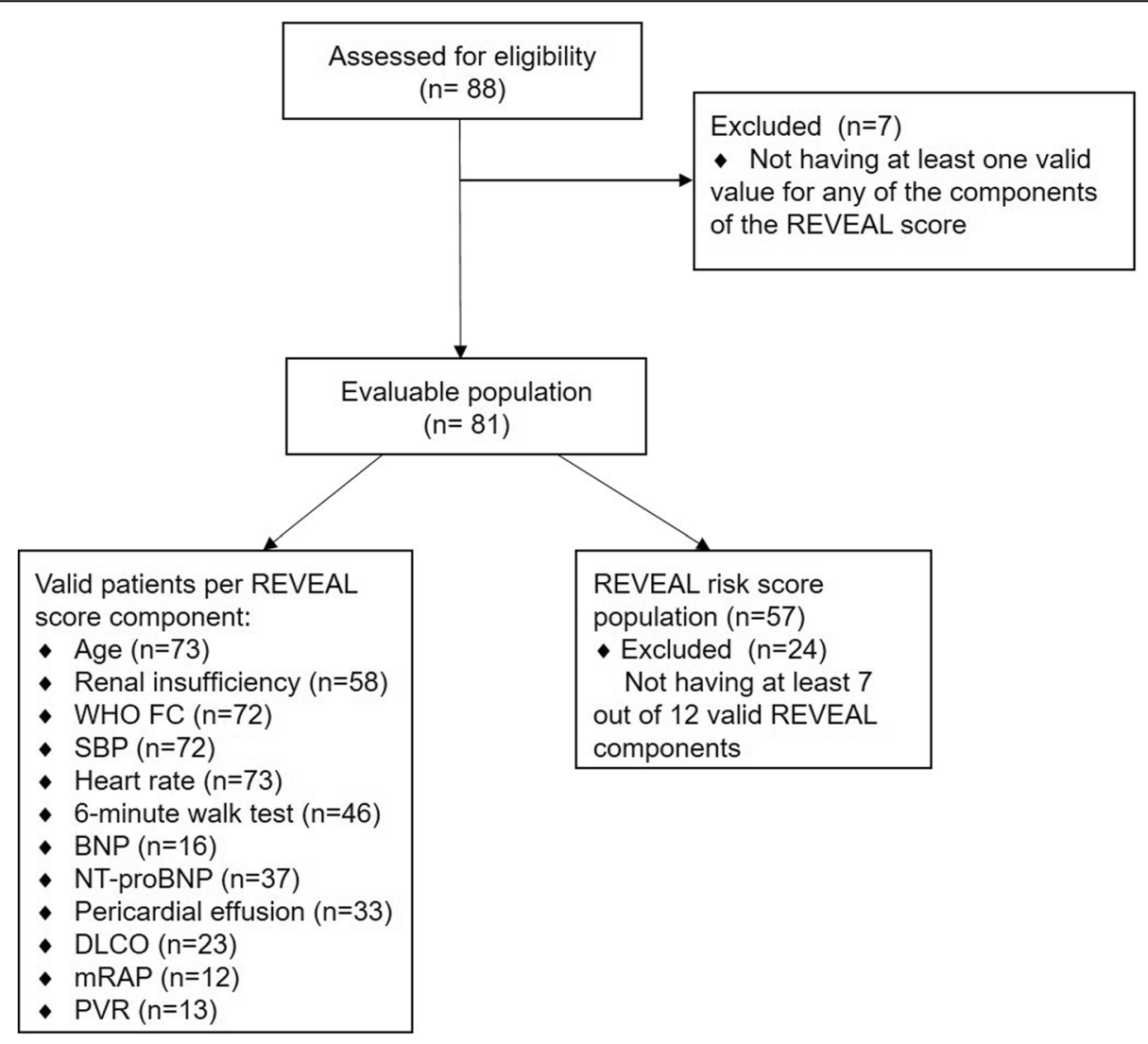

Fig. 1 Patient flow. BNP = brain natriuretic peptide; $D L C O=$ diffusing capacity of the lungs for carbon monoxide; FC = functional class; $m R A P=$ mean right atrial pressure; $\mathrm{NT}$-proBNP=N-terminal pro-BNP; $\mathrm{PVR}=$ pulmonary vascular resistance; $\mathrm{SBP}=$ systolic blood pressure; $\mathrm{WHO}=\mathrm{World}$ Health Organization 
Table 1 shows the main characteristics of the study cohorts at baseline. Prevalent patients were $59.3 \%$ of the overall population. The population was mostly female (77.8\%), and mean age of the overall population was 57.2 years. Idiopathic or heritable $\mathrm{PAH}$ was the most common PAH subgroup with $50.6 \%$ of patients. Fortytwo percent of patients were on macitentan as monotherapy $(66.7 \%$ of incident patients and $25.0 \%$ of prevalent patients) and $44.4 \%$ were on combination with a phosphodiesterase type 5 (PDE5) inhibitor (33.3\% of incident patients and $52.1 \%$ of prevalent patients), mainly sildenafil (80.6\%). Baseline characteristics were comparable between groups except that prevalent patients had significantly greater distance covered in the 6-min walk test than incident patients $(p<0.01)$.

Therapy for PAH was related to time since diagnosis. Patients on monotherapy (of the patients on monotherapy,
64.7\% were incident and $35.3 \%$ were prevalent) started macitentan after a median (Q1-Q3) of 3.3 (0.4-13.7) months after PAH diagnosis while patients on combination with a PDE5 inhibitor (of the patients on this combination, $30.6 \%$ were incident and $69.4 \%$ were prevalent) initiated macitentan after a median (Q1-Q3) of 23.0 (2.6-59.0) months. All patients on double or triple combination therapy with a prostacyclin were prevalent with a median (Q1Q3) time from $\mathrm{PAH}$ diagnosis to start of macitentan of 14.5 (8.8-120.2) months. The median (Q1-Q3) time of macitentan treatment was $10.5(8.1-13.1)$ months.

\section{Changes in REVEAL risk score}

At baseline, the mean REVEAL score was 8.7 points, and at $\geq 6$-month time point, it had decreased to 7.2 points. Overall, the mean change (95\% confidence interval) in REVEAL risk score over a period of at least six months

Table 1 Patient demographics and disease characteristics at baseline

\begin{tabular}{|c|c|c|c|}
\hline & Incident $(n=33)$ & Prevalent $(n=48)$ & Total $(n=81)$ \\
\hline Age, years, mean (SD) & $57.9(18.3)$ & $56.6(14.9)$ & $57.2(16.3)$ \\
\hline Sex, female & $24(72.7)$ & $39(81.3)$ & $63(77.8)$ \\
\hline \multicolumn{4}{|l|}{ WHO group I subgroup } \\
\hline Idiopathic or heritable PAH & $17(51.5)$ & $24(50.0)$ & $41(50.6)$ \\
\hline PAH associated with connective tissue disorders & $15(45.5)$ & $14(29.2)$ & $29(35.8)$ \\
\hline PAH associated with corrected simple congenital heart disease & $1(3.0)$ & $9(18.8)$ & $10(12.4)$ \\
\hline Time since PAH diagnosis, months, median (Q1-Q3) & $1.0(0.2-2.6)$ & $42.8(14.5-97.7)$ & $11.1(1.8-56.2)$ \\
\hline \multicolumn{4}{|l|}{ WHO FC } \\
\hline 1 & $1(3.0)$ & $2(4.2)$ & $3(3.7)$ \\
\hline$\|$ & $5(15.1)$ & $13(27.1)$ & $18(22.2)$ \\
\hline III & $21(63.6)$ & $30(62.5)$ & $51(63.0)$ \\
\hline IV & $6(18.2)$ & $3(6.3)$ & $9(11.1)$ \\
\hline Renal insufficiency, yes & $4(13.3)$ & 9 (19.6) & $13(17.1)$ \\
\hline SBP, mm Hg, mean (SD) & $117.9(16.0)$ & $122.2(17.9)$ & $120.4(17.2)$ \\
\hline Heart rate, beats/min, mean (SD) & $79.5(11.8)$ & $77.9(12.6)$ & $78.6(12.3)$ \\
\hline 6-min walk test, $\mathrm{m}$, mean $(\mathrm{SD})^{*}$ & $309.1(153.2)$ & $401.6(102.9)$ & $362.5(133.7)$ \\
\hline BNP, pg/mL, mean (SD) & $368.7(433.2)$ & $247.5(188.5)$ & $300.2(316.1)$ \\
\hline NT-proBNP, pg/mL mean (SD) & $1140.9(1451.3)$ & $1452.4(1995.5)$ & 1327.9 (1797.6) \\
\hline Pericardial effusion, yes & $4(12.9)$ & $4(8.9)$ & $8(10.5)$ \\
\hline DLCO, \% predicted, mean (SD) & $57.4(19.3)$ & $57.9(19.4)$ & $57.8(19.2)$ \\
\hline mRAP, mm Hg, mean (SD) & $11.7(10.7)$ & $10.3(8.1)$ & $10.9(9.3)$ \\
\hline PVR, WU, mean (SD) & $9.2(4.5)$ & $8.8(4.3)$ & $9.0(4.3)$ \\
\hline \multicolumn{4}{|l|}{ Therapy for $\mathrm{PAH}^{*}$} \\
\hline Macitentan monotherapy & $22(66.7)$ & $12(25.0)$ & $34(42.0)$ \\
\hline Macitentan + PDE5 inhibitor & $11(33.3)$ & $25(52.1)$ & $36(44.4)$ \\
\hline Macitentan + prostacyclin / Macitentan + PDE5 inhibitor + prostacyclin & $0(0)$ & $11(22.9)$ & $11(13.6)$ \\
\hline
\end{tabular}

Data are number of patients (percentage) except when otherwise indicated

$B N P$ brain natriuretic peptide, DLCO diffusing capacity of the lungs for carbon monoxide, FC functional class, mRAP mean right atrial pressure, NT-proBNP Nterminal pro-BNP, PAH pulmonary arterial hypertension, PDE5 phosphodiesterase type 5, PVR pulmonary vascular resistance, Q1 25th percentile, Q3 75th percentile, $S D$ standard deviation, SBP systolic blood pressure, WHO World Health Organization, WU Wood units

${ }^{*} p<0.01$ between incident and prevalent patients 
was $-1.4(-2.0,-0.9)$ points $(p<0.0001)$, and there was a significant reduction in REVEAL score for incident and prevalent patients (Table 2). According to treatment, the REVEAL risk score reduction was -1.2 $(-2.0,-0.5)$ points $(p=0.0050)$ and $-1.6(-2.7,-0.5)$ points $(p=0.0070)$ and, in patients on macitentan monotherapy and patients on combination with PDE5 inhibitor, respectively (Table 2 ).

The REVEAL risk score decreased (improved), remained unchanged, and increased (worsened) in $57.9,26.3$, and $15.8 \%$ of patients after at least 6month follow-up, respectively. The improvement in the REVEAL risk score was similar in both cohorts with $60.9 \%$ of incident patients and $55.9 \%$ of prevalent patients who improved the risk score after a minimum of 6-month follow-up.

\section{Changes in REVEAL risk strata}

Evolution of REVEAL risk score by risk stratum is shown in Table 3 and Fig. 2. After at least six months from baseline, the number of patients who were in the low and average-moderate high risk strata significantly increased (from 63.2\% [ $n=36]$ to $86.0 \%[n=49]$ ) while the number of patients who were in the high-very high risk strata decreased (from 36.8\% $[n=21]$ to $14.0 \%[n=$ 8]) (Fig. 2).

Patients with low REVEAL risk were mainly treated with macitentan monotherapy (around 60\% of patients both at baseline and after at least 6-month follow up) while patients with high or very high REVEAL risk score were on combination with macitentan and a PDE5 inhibitor (nearby $60 \%$ of patients both at baseline and after at least 6-month follow up).

\section{Individual components of the REVEAL score}

The main REVEAL individual components that significantly improved after at least six months were (Table 4): WHO FC (63.9\% FC III at the start of macitentan versus $23.6 \%$ after $\geq 6$-month period, $p<0.0001$ [Fig. 3]), 6-min walk test (mean change of $41.8 \mathrm{~m}, p<0.01$ ), BNP (mean change of $-157.6 \mathrm{pg} / \mathrm{mL}, p<0.05$ ), NT-proBNP (mean change of $-530.0 \mathrm{pg} / \mathrm{mL}, \mathrm{p}<0.01$ ), and PVR (mean change of $-3.4 \mathrm{WU}, \mathrm{p}<0.01$ ). Box plots for BNP and NT-proBNP values are shown in Fig. 4.

The greatest improvements in individual parameters of the REVEAL risk score were in WHO FC (with $62.5 \%$ of patients improved, and where $40.3 \%$ of patients improved from WHO FC III to FC II), BNP or NTproBNP (24.5\% of patients improved), and 6-min walk test $(23.9 \%$ of patients improved).

\section{Discussion}

The REVEAL risk score calculator was originally developed to predict survival in patients with PAH [6]. Benza et al. [6] showed that low REVEAL risk stratum was associated with a 1-year survival rate of $95-100 \%$ while higher scores were associated with lower survival rates. The PRACMA study assessed the change in REVEAL risk score in PAH patients receiving macitentan for the first time in clinical practice. In our study, treatment with macitentan improved REVEAL risk score by risk stratum. The study population had an average to moderate high risk at baseline (mean risk score of 8.7), which diminished to low risk (mean risk score of 7.2) after a median time of treatment with macitentan of 11 months. There was a significant increase in the number of patients in the low risk stratum after at least 6-month

Table 2 Changes in REVEAL risk score at $\geq 6$-month time point: overall and by time since diagnosis and PAH therapy

\begin{tabular}{|c|c|c|c|c|}
\hline & $\begin{array}{l}\text { Baseline score, } \\
\text { mean (SD) }\end{array}$ & $\begin{array}{l}\geq 6 \text {-month score, } \\
\text { mean (SD) }\end{array}$ & $\begin{array}{l}\text { Mean change } \\
(95 \% \mathrm{Cl})\end{array}$ & $p$-value \\
\hline Total $(n=57)$ & $8.7(2.4)$ & $7.2(2.4)$ & $-1.4(-2.0,-0.9)$ & $<0.0001$ \\
\hline Macitentan monotherapy $(n=25)$ & $7.8(2.2)$ & $6.5(2.4)$ & $-1.2(-2.0,-0.5)$ & 0.0050 \\
\hline Macitentan + PDE5 inhibitor $(n=25)$ & $9.5(2.3)$ & $7.9(2.5)$ & $-1.6(-2.7,-0.5)$ & 0.0070 \\
\hline Macitentan + prostacyclin / Macitentan + PDE5 inhibitor + prostacyclin $(n=7)$ & $8.9(2.3)$ & $7.4(2.2)$ & $-1.4(-2.7,-0.1)$ & 0.0308 \\
\hline Incident $(n=23)$ & $8.9(2.7)$ & $7.0(2.3)$ & $-1.8(-3.0,-0.7)$ & 0.0040 \\
\hline Macitentan monotherapy $(n=15)$ & $7.9(2.2)$ & $6.6(2.2)$ & $-1.3(-2.5,-0.2)$ & 0.0300 \\
\hline Macitentan + PDE5 inhibitor $(n=8)$ & $10.6(2.7)$ & $7.9(2.4)$ & $-2.8(-5.8,-0.3)$ & 0.0650 \\
\hline Prevalent $(n=34)$ & $8.5(2.2)$ & $7.4(2.6)$ & $-1.2(-1.8,-0.5)$ & 0.0010 \\
\hline Macitentan monotherapy $(n=10)$ & $7.5(2.3)$ & $6.4(2.8)$ & $-1.1(-2.2,0.04)$ & 0.0707 \\
\hline Macitentan + PDE5 inhibitor $(n=17)$ & $9.0(2.0)$ & $8.0(2.6)$ & $-1.1(-2.1,-0.04)$ & 0.0516 \\
\hline Macitentan + prostacyclin / Macitentan + PDE5 inhibitor + prostacyclin $(n=7)$ & $8.9(2.3)$ & $7.4(2.2)$ & $-1.4(-2.7,-0.1)$ & 0.0308 \\
\hline
\end{tabular}

Significant $p$-values are marked in bold

Cl confidence interval, PDE5 phosphodiesterase type 5, SD standard deviation 
Table 3 Distribution of patients by REVEAL risk categories at baseline and $\geq 6$-month time points in patients on macitentan

\begin{tabular}{lllllll}
\hline & \multicolumn{3}{l}{$\geq 6$-month } & & & \\
\cline { 2 - 6 } Baseline & $1-7$ & 8 & 9 & $10-11$ & $\geq 12$ & Total \\
\hline $1-7$ & 12 & 2 & 0 & 0 & 0 & 14 \\
8 & 5 & 2 & 3 & 0 & 0 & 10 \\
9 & 3 & 3 & 6 & 0 & 0 & 12 \\
$10-11$ & 4 & 4 & 3 & 5 & 1 & 17 \\
$\geq 12$ & 1 & 0 & 1 & 2 & 0 & 4 \\
Total & 25 & 11 & 13 & 7 & 1 & 57
\end{tabular}

Risk categories: 1-7 low risk, 8 average risk, 9 moderate high risk, 10 or 11 high risk, and $\geq 12$ very high risk

follow-up period ( $20 \%$ more patients) and thus, an improvement in survival prognosis in these PAH patients was possible. On the other hand, around $23 \%$ less patients were in the highest risk strata after treatment with macitentan. Currently, other approaches to assess risk or risk stratification in $\mathrm{PAH}$ would include the use of risk variables according to the latest European Society of Cardiology (ESC)/ European Respiratory Society (ERS) guidelines for pulmonary hypertension [2], categorizing risk as low, intermediate or high with increasing estimated 1-year mortality. However, these guidelines were published after the PRACMA study had been started and thus, were not considered for risk analysis.

Moreover, treatment with macitentan significantly improved the REVEAL risk score in PAH patients with a mean decrease of 2 points in incident patients and a mean decrease of 1 point in prevalent patients. Improvements were maintained by treatment groups, either macitentan monotherapy, double combination with
PDE5 inhibitor, or double or triple combination with prostacyclin subgroup. Overall, these findings are in accordance with previous data from the REVEAL cohort of Benza et al. [11] who found that incident patients were more likely to have decreased scores compared with prevalent patients ( $41 \%$ versus $28 \%$ of patients). These authors also reported $32 \%$ of patients with a decrease in the REVEAL risk score (58\% in our study), 38\% of patients with no change in the risk score $(26 \%$ in our study), and $30 \%$ with an increase in the risk score $(16 \%$ in our study) after 12 months of follow-up.

The REVEAL risk score has recently been applied to PAH patients treated with a guanylate cyclase stimulator [12], supporting its utility in predicting patient survival in a controlled population. Benza et al. [12] reported a significant change from baseline in REVEAL risk score ( -0.6 points) after 12 weeks of riociguat compared with placebo (- 0.1 points). By contrast, PRACMA was an observational study enrolling patients in real clinical practice and with longer follow-up.

By individual REVEAL component, treatment with macitentan significantly improved 6 out of 12 REVEAL components including WHO FC as well as the levels of BNP and NT-proBNP, and 6-min walk test results after at least six months of treatment, all of them determinants of PAH prognosis.

The previous phase III Seraphin study [10], which examined the efficacy and safety of macitentan, included a large number of PAH patients. Our population from several centres in Spain was representative of clinical practice for the treatment of PAH with macitentan. Overall, demographic data was consistent with that of the registries of PAH [13-15]. Comparison of demographic

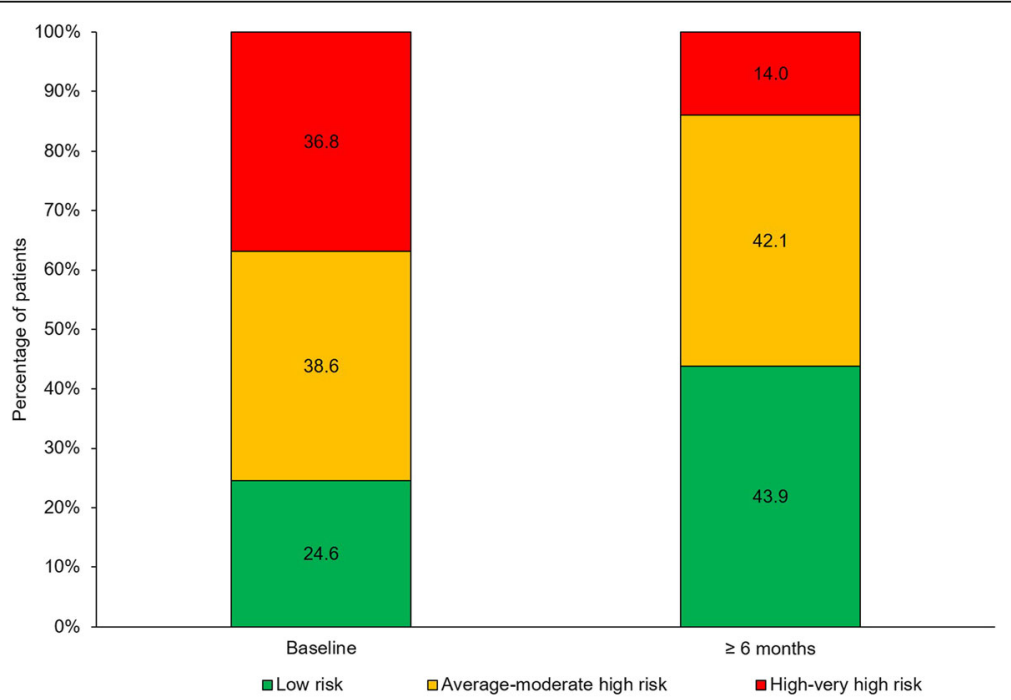

Fig. 2 Evolution of REVEAL risk strata after at least six months on macitentan. Grouped risk categories: 1-7 low risk, 8-9 average-moderate high risk, $\geq 10$ high-very high risk 
Table 4 Changes in individual REVEAL components at $\geq 6$-month time point

\begin{tabular}{|c|c|c|c|c|c|}
\hline Component & $n$ & Baseline score, mean (SD) & z6-month score, mean (SD) & Mean change $(95 \% \mathrm{Cl})$ & $p$-value \\
\hline WHO FC (as continuous) & 72 & $2.1(0.7)$ & $2.8(0.7)$ & $-0.7(-0.8,-0.5)$ & $<0.0001$ \\
\hline $\mathrm{SBP}, \mathrm{mm} \mathrm{Hg}$ & 72 & $120.4(17.1)$ & $117.9(15.6)$ & $-2.5(-6.4,1.4)$ & 0.0476 \\
\hline Heart rate, beats/min & 73 & $77.8(12.1)$ & $77.0(13.8)$ & $-0.8(-4.3,2.8)$ & 0.5057 \\
\hline 6-min walk test, $\mathrm{m}$ & 46 & $364.5(133.3)$ & $406.3(112.3)$ & $41.8(14.5,69.2)$ & 0.0003 \\
\hline BNP, $\mathrm{pg} / \mathrm{mL}$ & 16 & $310.1(350.2)$ & $152.5(164.8)$ & $-157.6(-336.3,-21.1)$ & 0.0229 \\
\hline NT-proBNP, pg/mL & 37 & $1121.1(1497.4)$ & $590.6(630.4)$ & $-530.0(-972.0,-88.9)$ & 0.0014 \\
\hline DLCO, \% predicted & 23 & $52.7(18.0)$ & $50.8(19.2)$ & $-1.9(-1.6,5.5)$ & 0.2753 \\
\hline mRAP, $\mathrm{mm} \mathrm{Hg}$ & 12 & $7.9(4.0)$ & $7.7(2.6)$ & $-0.3(-1.6,2.1)$ & 0.4939 \\
\hline PVR, WU & 13 & $11.5(4.6)$ & $8.1(3.4)$ & $-3.4(-6.5,-0.2)$ & 0.0033 \\
\hline
\end{tabular}

Significant $p$-values are marked in bold

$B N P$ brain natriuretic peptide, $C l$ confidence interval, $D L C O$ diffusing capacity of the lungs for carbon monoxide, $F C$ functional class, mRAP mean right atrial pressure, NT-proBNP N-terminal pro-BNP, PAH pulmonary arterial hypertension, PVR pulmonary vascular resistance, Q1 25th percentile, Q3 75th percentile, SD standard deviation, SBP systolic blood pressure, WHO World Health Organization, WU Wood units

characteristics showed similar sex ratio but higher mean age in our population, 46 years in Seraphin study [10] versus 57 years in our study, probably due to the noncontrolled design. Also, similar percentages of incident and prevalent patients among treatment-naïve patients were found in the Seraphin pivotal trial, 41 and 59\%, respectively [16], although PAH treatment eras between enrolment in Seraphin and PRACMA studies were different. At 12-month follow-up of the REVEAL cohort [11], 35\% of incident patients and $54 \%$ of prevalent patients were on combination therapy (consistent with 33 and $52 \%$ showed in our study), and $25 \%$ of incident patients and $34 \%$ of prevalent patients were receiving prostanoids. Although most of prevalent patients in our study were treated in combination therapy for PAH, there were 12 prevalent patients (35\%) who reported macitentan as monotherapy. A switch from a previous endothelin receptor antagonist [17] could be one of the reasons. As expected, all patients on triple combination with a PDE5 inhibitor and a prostacyclin in clinical practice were prevalent.

Our study has several limitations. First, this was a retrospective study with data collection from medical records resulting in potential selection bias. Second, as idiopathic and heritable PAH were collected together, we were not able to differentiate familial PAH, which sums two points for the REVEAL risk score. This would not affect the change over time but the REVEAL score could be overestimated. Also, not all WHO group I PAH subgroups were included (e.g. PAH associated with portal hypertension). Third, we did not know for how long patients on combination therapy were receiving PDE5 inhibitor or prostacyclin nor if they were on stable doses prior to macitentan initiation. It is also important

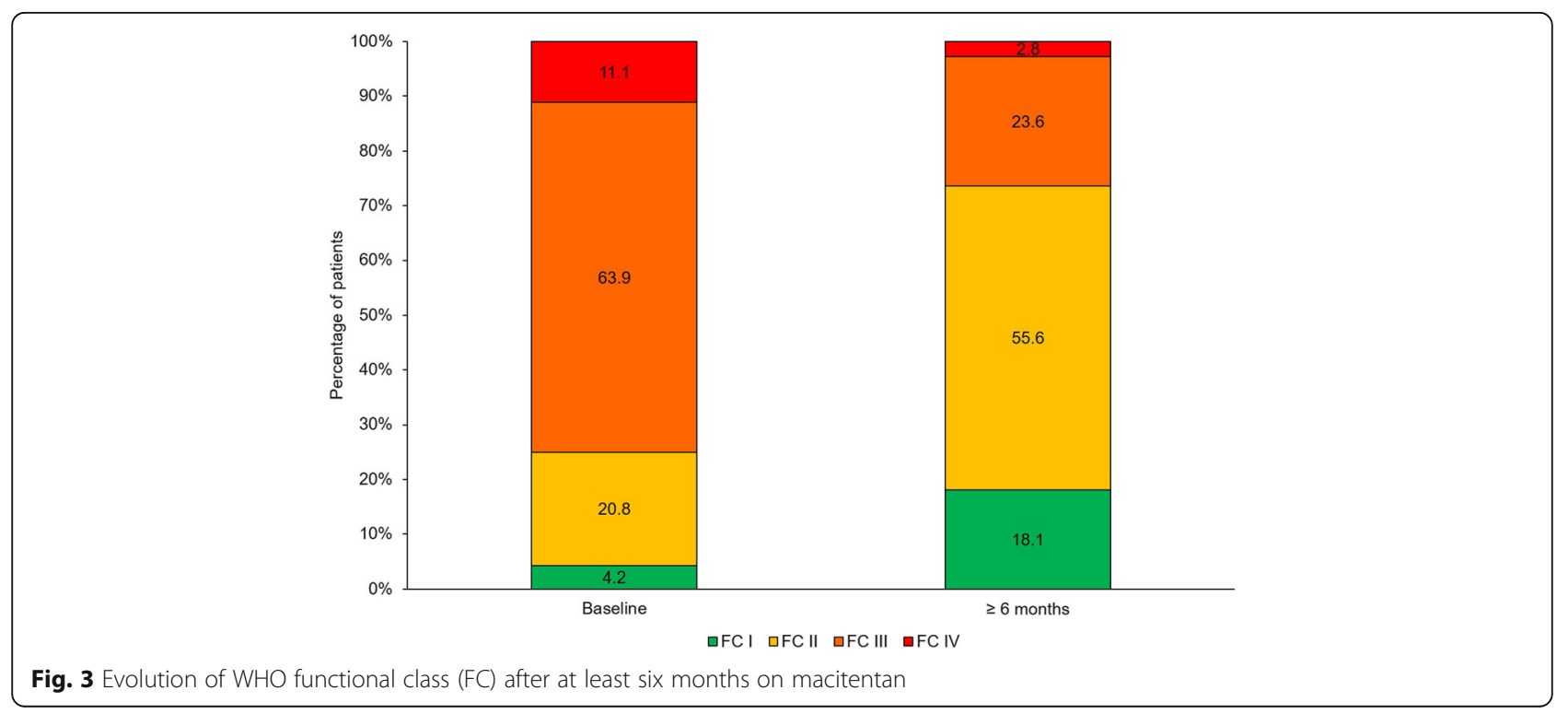



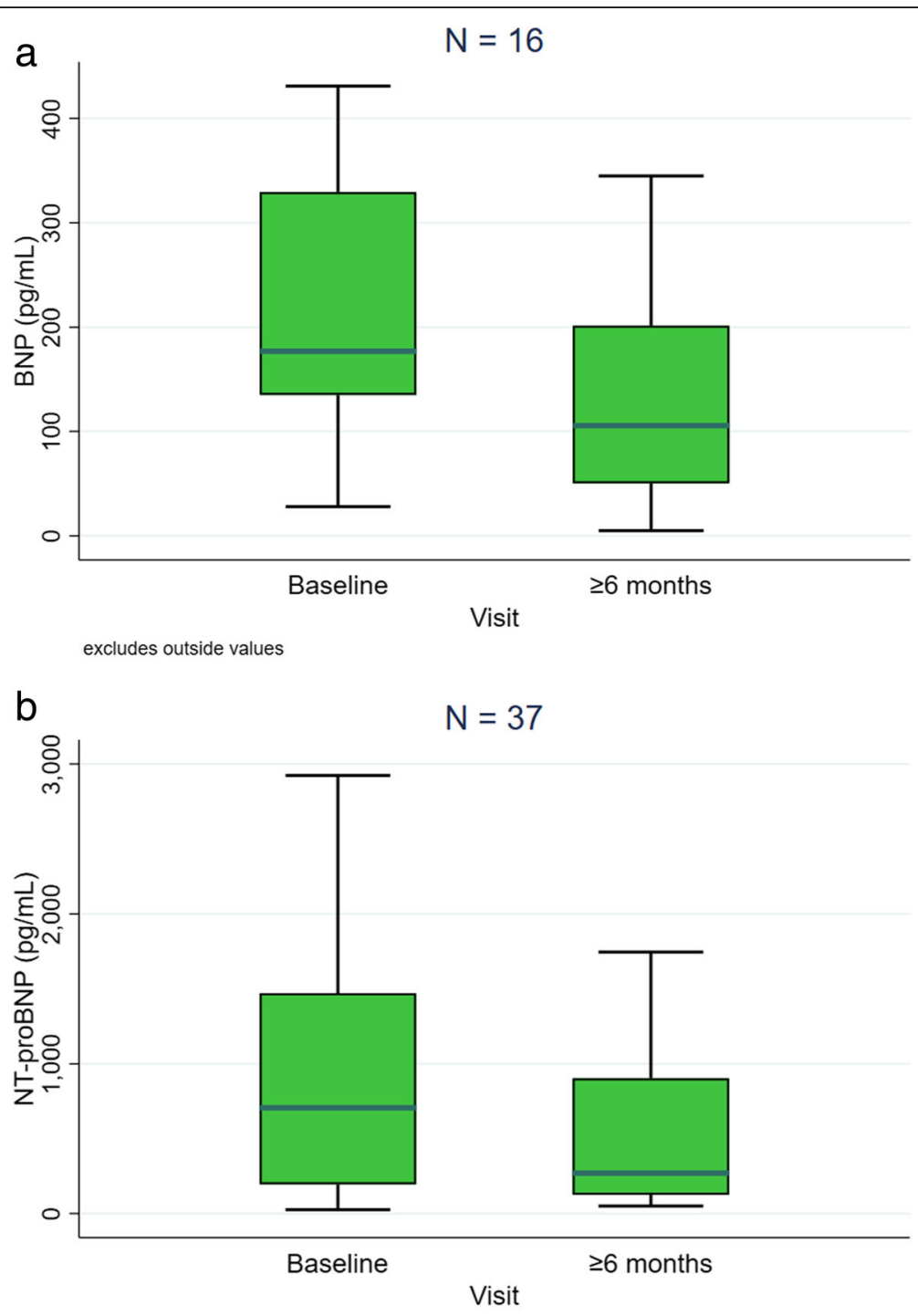

excludes outside values

Fig. 4 Box plots for brain natriuretic peptide (BNP) [a] and N-terminal proBNP (NT-proBNP) [b] data at baseline and $\geq 6$-month time points in patients on macitentan. The box spans data values between the two quartiles (25th and 75th percentiles), with the horizontal line within the box marking the median value. The upper and lower limits represent 75 th percentile + (interquartile range*1.5) and 25th percentile - (interquartile range*1.5), respectively

to note that concomitant diseases or medications were not recorded, and we were not able to assess their impact on the REVEAL risk score (for instance, diuretic treatment is known to be related to BNP levels [18]). Also, the PRACMA study did not evaluate the association of the risk score with survival. Finally, safety was not assessed (adverse events were not recorded in PRACMA study) because it was not a study objective.

Besides, current multifactorial assessment tools for measuring risk in $\mathrm{PAH}$ remain far from becoming mainstream tests in clinical practice. REVEAL risk score cannot be routinely applied to a high number of $\mathrm{PAH}$ patients. Recently, a modified risk assessment score of $\mathrm{PAH}$, comprising four non-invasive variables, which could be more simply used in daily clinical setting than the REVEAL risk score has been published with promising results [19].

\section{Conclusion}

In conclusion, in this study, treatment with macitentan improved the REVEAL risk strata and REVEAL risk score in incident and prevalent PAH patients, either in patients on monotherapy or on combination in clinical practice after at least six months of macitentan treatment. Further prospective studies are required to confirm these results and relate to survival prognosis in patients with PAH in clinical practice. 


\section{Abbreviations}

BNP: Brain Natriuretic Peptide; DLCO: Diffusing Capacity of the Lungs for Carbon Monoxide; FC: Functional Class; mRAP: mean Right Atrial Pressure; NT-proBNP: N-terminal pro-Brain Natriuretic Peptide; PAH: Pulmonary Arterial Hypertension; PDE5: Phosphodiesterase Type 5; PVR: Pulmonary Vascular Resistance; REVEAL: Registry to Evaluate Early and Long-term PAH Disease Management; SBP: Systolic Blood Pressure; WHO: World Health Organization; WU: Wood Units

\section{Acknowledgements}

Manuscript writing and editorial support was provided by Eva Mateu, PhD from TFS S.L. with financial support provided by Actelion Pharmaceuticals España S.L.

Investigators of the PRACMA Study are as follows: Dr. Luis Almenar (Hospital La Fe); Dr. José Manuel Alvarez Dobaño (C.H.U. Santiago); Dr. Adolfo Baloira (Hospital de Pontevedra); Dra. Julia Barbado (Hospital Clínico de Valladolid); Dr. Pedro Bedate Diaz (HUCA Oviedo); Dra. Isabel Blanco (Hospital Clínic); Dr. David Blanquer (Hospital Fundació de Manacor); Dra. Ana José Bustamante Ruiz (Hospital Sierrallana); Dr. Sergio Cadenas (Hospital de Salamanca); Dr. Ignacio Casado (Hospital Virgen de las Nieves); Dr. Carlos Chamorro (Hospital Virgen de los Lirios); Dr. José Manuel Cifrian (Hospital Marqués de Valdecilla); Dr. David Cremer (Hospital Son Llatzer); Dra. Eva Delgado (Hospital Fundació de Manacor); Dr. Juan Luis Delgado (Hospital Rio Carrión); Dr. Juan Antonio Domingo (Hospital Miguel Servet); Dra. Pilar Escribano (Hospital 12 Octubre); Dr. Luis García Arangüena (Hospital Sierrallana); Dr. Juan Pablo García Muñoz (Hospital Universitario de Burgos); Dr. David Iturbe (Hospital Marqués de Valdecilla); Dr. Antonio Lara (Hospital Universitario de Tenerife); Dra. María Lázaro (Hospital de Toledo); Dr. Manuel López Meseguer (Hospital Vall d'Hebron); Dra. Raquel López (Hospital La Fe); Dra. Ana Madroñero (Hospital San Jorge); Dra. Adela Marín (Hospital Lozano Blesa); Dr. Lluis Molina Ferragut (Hospital del Mar); Dr. Eduardo Moreno Escobar (Hospital Virgen de las Nieves); Dra. Ana Núñez (Hospital de Albacete); Dr. Juan Ortiz de Saracho y Bobo (Hospital del Bierzo); Dra. Cilia Amparo Peralta (Hospital Lozano Blesa); Dr. Gregorio Pérez Peñate (Hospital Universitario General de Gran Canaria Doctor Negrín); Dr. Javier Pomares Amigó (Hospital Parc Taulí); Dr. Carlos Rodriguez (Hospital de Melilla); Dr. Vicente Roig (Hospital Clínico de Valladolid); Dr. Ximo Rueda (Hospital La Fe); Dr. Ernest Sala (Hospital Son Espases); Dra. Rafaela Sánchez Simón (Hospital de Albacete).

\section{Authors' contributions}

$P E-S, R L, L A, M L, I B$, and JAB substantially contributed to the conception or design of the work, interpreted the patient data, drafted the work and revised it critically for important intellectual content. IF and AT substantially contributed to the conception or design of the work. All authors read and approved the final manuscript.

\section{Funding}

The design of the study, data collection, analysis, interpretation of data and manuscript writing was sponsored by Actelion Pharmaceuticals España S.L.

\section{Availability of data and materials}

The datasets used and/or analysed during the current study are available from the corresponding author on reasonable request.

\section{Ethics approval and consent to participate}

The protocol was approved by the independent ethics committee at Hospital universitario y politécnico la Fe (e-mail: ceic@iislafe.es, protocol reference number: ACT-MAC-2015-01) and all patients provided written informed consent before participation.

\section{Consent for publication}

\section{Not applicable.}

\section{Competing interests}

PE has received has received consulting/speaker fees and advisory board from Actelion Pharmaceuticals España S.L; Bayer, GlaxoSmithKline and Merck Sharp \& Dohme, her institution has received grant support from Actelion Pharmaceuticals España S.L; Bayer, GlaxoSmithKline and Ferrer, and has received honoraria for her collaboration in the PRACMA study. RL has received honoraria for her collaboration in the PRACMA study. ML has received honoraria for her collaboration in the PRACMA study, and educational and consulting honoraria from Actelion Pharmaceuticals España S.L. IA and AT were employees of Actelion Pharmaceuticals España S.L. IB has received honoraria for her collaboration in the PRACMA study. JAB has received honoraria for consultation or speaker fees from Actelion and Merck; research support through his institution from Actelion, Merck, GlaxoSmithKline and Ferrer; and has received honoraria for his collaboration in the PRACMA study.

\section{Author details}

${ }^{1}$ Pulmonary Hypertension Unit, Cardiology Department, Hospital Universitario 12 de Octubre, Av. Córdoba, s/n, 28041 Madrid, Spain. ${ }^{2}$ CIBER de Enfermedades Cardiovasculares (CIBERCV), Instituto de Investigación Sanitaria Hospital 12 de Octubre (imas12), Av. Córdoba, s/n, 28041 Madrid, Spain. ${ }^{3}$ Pulmonary Service, Hospital Universitari i Politècnic La Fe, València, Spain. ${ }^{4}$ Cardiology Department, Hospital Virgen de la Salud, Toledo, Spain. ${ }^{5}$ Actelion Pharmaceuticals España S.L., Barcelona, Spain. ${ }^{6}$ Pulmonary Service, Hospital Clínic, Institut d'Investigacions Biomèdiques August Pi i Sunyer (IDIBAPS), Barcelona, Spain.

Received: 28 August 2019 Accepted: 22 May 2020

Published online: 02 June 2020

\section{References}

1. Simonneau G, Gatzoulis MA, Adatia I, Celermajer D, Denton C, Ghofrani A, et al. Updated clinical classification of pulmonary hypertension. J Am Coll Cardiol. 2013;62(25 Suppl):D34-41.

2. Galiè N, Humbert M, Vachiery J-L, Gibbs S, Lang I, Torbicki A, et al. 2015 ESC/ERS guidelines for the diagnosis and treatment of pulmonary hypertension: the joint task force for the diagnosis and treatment of pulmonary hypertension of the European Society of Cardiology (ESC) and the European Respiratory Society (ERS): endorsed by: Association for European Paediatric and Congenital Cardiology (AEPC), International Society for Heart and Lung Transplantation (ISHLT). Eur Heart J. 2016;37(1):67-119.

3. McGoon MD, Benza RL, Escribano-Subias P, Jiang X, Miller DP, Peacock AJ, et al. Pulmonary arterial hypertension: epidemiology and registries. J Am Coll Cardiol. 2013;62(25 Suppl):D51-9.

4. Peacock AJ, Murphy NF, McMurray JJV, Caballero L, Stewart S. An epidemiological study of pulmonary arterial hypertension. Eur Respir J. 2007; 30(1):104-9.

5. Jiménez C, Escribano P, Barberà J, Román A, Sánchez Román J, Morales P. Epidemiología de la HAP en España: análisis preliminar del Registro Español de Hipertensión Pulmonar (REHAP). Rev Esp Cardiol. 2009;62(3 Suppl):58.

6. Benza RL, Gomberg-Maitland M, Miller DP, Frost A, Frantz RP, Foreman AJ, et al. The REVEAL registry risk score calculator in patients newly diagnosed with pulmonary arterial hypertension. Chest. 2012;141(2):354-62.

7. Benza RL, Miller DP, Gomberg-Maitland M, Frantz RP, Foreman AJ, Coffey CS, et al. Predicting survival in pulmonary arterial hypertension: insights from the registry to evaluate early and long-term pulmonary arterial hypertension disease management (REVEAL). Circulation. 2010;122(2):164-72.

8. Benza RL, Miller DP, Barst RJ, Badesch DB, Frost AE, McGoon MD. An evaluation of long-term survival from time of diagnosis in pulmonary arterial hypertension from the REVEAL registry. Chest. 2012;142(2):448-56.

9. Channick RN, Sitbon O, Barst RJ, Manes A, Rubin LJ. Endothelin receptor antagonists in pulmonary arterial hypertension. J Am Coll Cardiol. 2004; 43(12 Suppl S):62S-7S

10. Pulido T, Adzerikho I, Channick RN, Delcroix M, Galiè N, Ghofrani H-A, et al. Macitentan and morbidity and mortality in pulmonary arterial hypertension. N Engl J Med. 2013;369(9):809-18.

11. Benza RL, Miller DP, Foreman AJ, Frost AE, Badesch DB, Benton WW, et al. Prognostic implications of serial risk score assessments in patients with pulmonary arterial hypertension: a registry to evaluate early and long-term pulmonary arterial hypertension disease management (REVEAL) analysis. J Heart Lung Transplant. 2015;34(3):356-61.

12. Benza RL, Farber HW, Frost A, Ghofrani H-A, Gómez-Sánchez MA, Langleben D, et al. REVEAL risk scores applied to riociguat-treated patients in PATENT-2: impact of changes in risk score on survival. J Heart Lung Transplant. 2018;37(4):513-9.

13. Awdish R, Cajigas H. Definition, epidemiology and registries of pulmonary hypertension. Heart Fail Rev. 2016;21(3):223-8.

14. Sitbon O, Benza RL, Badesch DB, Barst RJ, Elliott CG, Gressin V, et al. Validation of two predictive models for survival in pulmonary arterial hypertension. Eur Respir J. 2015;46(1):152-64. 
15. Ling Y, Johnson MK, Kiely DG, Condliffe R, Elliot CA, Gibbs JSR, et al. Changing demographics, epidemiology, and survival of incident pulmonary arterial hypertension: results from the pulmonary hypertension registry of the United Kingdom and Ireland. Am J Respir Crit Care Med. 2012;186(8):790-6.

16. Simonneau G, Channick RN, Delcroix M, Galiè N, Ghofrani H-A, Jansa P, et al. Incident and prevalent cohorts with pulmonary arterial hypertension: insight from SERAPHIN. Eur Respir J. 2015;46(6):1711-20.

17. Safdar Z, Thakur A, Frost A. Tolerability of switch to Macitentan from Bosentan in pulmonary arterial hypertension. South Med J. 2017;110(3):223-8.

18. Maron BA, Waxman AB, Opotowsky AR, Gillies H, Blair C, Aghamohammadzadeh $\mathrm{R}$, et al. Effectiveness of spironolactone plus ambrisentan for treatment of pulmonary arterial hypertension (from the [ARIES] study 1 and 2 trials). Am J Cardiol. 2013;112(5):720-5.

19. Xiong $W$, Zhao Y, Xu M, Pudasaini B, Guo X, Liu J. A modified risk score in one-year survival rate assessment of group 1 pulmonary arterial hypertension. BMC Pulm Med. 2018;18(1):161.

\section{Publisher's Note}

Springer Nature remains neutral with regard to jurisdictional claims in published maps and institutional affiliations.

Ready to submit your research? Choose BMC and benefit from:

- fast, convenient online submission

- thorough peer review by experienced researchers in your field

- rapid publication on acceptance

- support for research data, including large and complex data types

- gold Open Access which fosters wider collaboration and increased citations

- maximum visibility for your research: over $100 \mathrm{M}$ website views per year

At BMC, research is always in progress.

Learn more biomedcentral.com/submissions 